\title{
DOCUAENTARIO
}

\section{PELOTAS ANTIGA}

\section{IMPRESSŌES DE UM MEDICO ALEMAO EM 1858 (1)}

(Traduģăo de Theodoro Cabral) (2):

No entretanto, logo na manhã seguinte à minha chegada a Rio Grande, arrisquei uma pequena excursão, pelo menos a Pelotas. A ligação entre as duas cidades é feita por uma linha especial de navegação a vapor, duas vêzes por semana.

En 18 de maio já eu me achava na extremidade inferior da lagoa dos Patos, no terceiro vapor em que viajei. Felizmente logo a rota mudou para oeste; digo felizmente, porque na margem oriental đa extremiáade inferior da lagoa há morros de areia após morros de areia, cadia um dos quais, embora se pudesse ganhar um lado aprazível das cenas da natureza, é desesperadoramente fastidioso. Aquj a vista se espraia, com esfôrço, sôbre a areia sem vegetação, sem gozar sequer uma nesga de paisagem agradável. Com razão é chamado. aquêle mar de areia "areia gorda". Falta à margem deserta até o peculiar encanto que, alhures, the dăo os bandos de pássaros. Apenás se descobre uma ou outra curicaca, apenas aigumas aves aquáticas se balaçam sôbre o móvel elemento. Avista-se, todavia, certo: número daquela ave semelihante ao cisne, de pescoço e cabeça pretos, Anas zipgricolis.

Bem perto da embocadura do rio São Gonçalo, o rio que une as: duas lagoas, se eleva da. água um triste monumento. Aqui naufragou um navio de ferro, a vapor, dos laboriosos irmãos Diel mas nenhum homem pereceu; creio, porém, que em razäo do ferimento recebido ao explodir a caldeira, morreu um Diel, o comandante do navio. S6: as rodas aparecem fora da água e hả muito se renunciou à tentativa de fazer flutuar a embarcação.

\footnotetext{
(1). - Iixcerto do livro ae Avé-Lallement, Robert - Relse durch Sua-Brastlien im Jahre 1858. Leipzig, F. A. Brockhaus, $18 \%$, 2 vols., $509+$ 450 págs., liust. A tradução integral da obra será publicada, dentro em breve, pelo Instituto Nacional do Livro.

(2). - Do Instituto Nacional do Livro (Rio de Janeiró).
} 
Quando nos dirigimos à embocadura do Rio São Gonçalo, descobri ao norte da lagoa, ainda alta, a fumaça do Amélia, no qual, na véspera, eu chegara de Pôrto-Alegre. O Marquês de Caxias já o precedera com o correio e os passageiros do Rio. Assim, pois, na lagoa dos Patos já está o vapor em plena atividade.

Simples e aprazível é a toz do São Gonçalo. Há, à direita e à esquerda, campinas planas, quase pantanosas, onde vivem legiões de aves de todos os tamanhos. Ao lado das galinholas andam grandes garças e as mictérias, semelhantes a cegonhas, em original marcha de prarada, buscam o seu alimento.

Pouco depois vimos um grupo mais animado. Um rebanho de gado devia ser passado de uma das margens para a outra ou antes ser conduzido para os matadouros, onde o aguardava a faca assassina. Os animais pareciam pressentí-los; estavam inquietos e corriam de um lado para outro. Um grande touro negro ficou furioso; seis cavaleiros semi-nus perseguiam-no com os seus laços e, gritando e açulando, manobram os seus ligeiros cavalos com rara habilidade. Um dêles apanhou o touro enfurecido com o laço; mas o forte animal arrastou o cavalo e o cavaleiro para um terreno pantanoso e aproveitou a vantagem do terreno. $\mathrm{O}$ cavaleiro teve que soltar laço; o touro precipitou-se dentro do mato e atrás dêle se precipitaram os seis vaqueiros e desapareceram de nossa vista.

Cada vez mais se aproximava a margem do rio; apareciam bonitos grupos de casas e a embocadura de um pequeno rio vindo do norte, o rio Pelotas, a cujas margens se estendem estabelecimentos, de caráter verdadeiramente romântico, a certos respeitos, mas, por outro lado, realmente repugnante.

Em tôda a região há um horrível cheiro de carniçal Couros, chifres, cascos, ossos, tendốes, tripas e nauseantes massas de sangue em putrefação e, além disso, campos inteiros com carne dependurada, formavam um verdadeiro monturo em grande estilo e assinalam o distrito onde encontra o seu centro o mais importante ofício da província, que é abater bois e cavalos, principalmente éguas. Uma multidão de abutres sobrevoa a região ou ceva-se em sangue putrefacto!

Por mais aprazível que seja o pôrto de Pelotas; por mais largas: retas e em parte bonitas ruas que tenha a cidade que fica a um quarto de milha acima - neste matadouro extingue-se qualquer impressão de graça e de limpeza; em tôda parte cheira mal!

Vêem-se couros secos em tôdas as lojas, em todos os cantos e recantos há couros secando: Couros e Companhia é a grande firma da cidade e quem neles não achar prazer ou vantagem pode, sem grande perda, deixar de ir a Pelotas.

400.000 reses são abatidas anualmente em Pelotas, repugnante atascamento no sangue e nas imundíces dos animais, em que quase se animaliza a alma de magarefe dos homens. Não era tempo de matança, o que muito estimei; do contrário, eu teria que contem- 
plá-la e isso poderia pertubar todo o prazer de minha viagem no Rio Grande.

Por outro lado, com a minha viagem eu visava fins muito mais pacíficos. Queria visitar, ali, uma incipiente colônia alemã, empreendimento de um alemão, Jakob Rheingantz. Mas aconteceu que dificilmente eu podẹria, de Pelotas, alcançá-la num dia. E como, no dia seguinte, eu tinha de regressar e chegar a Rio Grande para alcançar a partida do paquete Imperador, tive de renunciar àquela visita.

Em compensação recebi muitas notícias sôbre a nova colônia alemã. O empresário Jakob Rheingantz está há uns dezessete anos no Brasil, trabalhou em diferentes posições num navio a vapor e parece nunca ter conseguido posição importante e nunca pôde fazer a sua feltcidade, de modo que com alguma prudência se pode cons'derar o seu empreendimento colonizador como o último meio de ganhar posição e o seu intento. Sob condições módicas êle obteve terras do govêrno, que sob condições iníquas revende aos imigrantes cobrando-lhes altos juros quando êstes não podem pagar. Todavia está dedicado de corpo e alma à sua emprêsa.

Uma emprêsa colonizadora irlandesa, muito mais próxima de Pelotas, parece ter-se malogrado. Pelos menos quase todos os colozos, que ali encontraram um solo desfavorável, säiram e se passaram para Montevidéu.

Os pelotenses, porém, cujas condições de vida de um modo geral, parecem piorar, desejam ansiosamente que se desenvolvam colônias em sua vizinhança, para com isso haurirem novas fôrças vitais e terem uma vida local mais importante. Assim, pois, o govêrno provincial pretende instalar em Pelotas uma extensa colônia, notadamente de alemães. Para isso foram dados os primeiros passos; foi pesquisado un pedaço de terra que se estende ao norte de Pelotas em direção a Serra dos Tapes e em parte é regado pelo pequeno mas aproveitável rio Pelotas. Deve-se aguardar o futuro desenvolvimento dessa colônia. Se todos os imigrantes que chegam e se dirigem a Relotas e às regiäes distantes, ao Uruguai, ao norte a ao noroeste da província, forem ajudados na mesma proporção em que se Feseja a sara vinda, com isso ambas as partes serão servidas. Só no auxílio mútuo e na assistência repousam o desenvolvimento e prosperidade de ambas.

Enquanto se aproxima a esperança e perspectiva de uma colonização das margens do Rio São Gonçalo e especialmente da cidade de Pelotas, desde alguns anos se tem desenvolvido um ramo industrial que, cuidado por mãos laboriosas, produz bons frutos. Comecou-se a trabalhar industrialmente, no próprio local, a enorme quantidado de matéria animal que antes era exportada como matéria prima para o estrangeiro e em parte se perdia.

De tổas as emprêsas similares em Pelotas e em tôda a província e talvez em todo o Brasil, está em primeiro lugar a fábrica de 
um alemão, o senhor Eggers, de Hamburgo, e como tal merece particular menção.

Para um jovem de civilização e sentimentos europeus, de dezoito anos, não deve ter sido pouca coisa abraçar nas margens do Rto Pelotas um negócio de modo algum agradável, cuja primeira instalação estava em decadência e a êle consagrar dezessete anos de vida com zêlo, seriedade e profundos conhecimentos tecnoĺogicos, para levá-lo ao seu atual aperfeiçoamento.

Aqui não posso descrever pormenorizadamente, as velas e colas do senhor Eggers. Bem perto da margem do pequeno e navegável Pelotas, foi construido um espaçoso e apropriado edifício, de acôrdo com um plano inteligente, dotado com uma cuidadosa escolha de aparelhos a vapor, como caldeiras para fundir, máquinas de cortar e providos de trithos à margem do rio, de modo que os produtos do hábil fabricante podem se exportados diretamente em ernbarcações próprias .

Reflita-se sôbre as dificuldades que oferece tal empreendimento na sua primeira instalação e em tornar conhecidos os produtos, em concorrência com os artigos europeus importados, dar-se-á ao senhor Eggers um lugar muito honroso entre os meritosos iniciadores: e promotores da indústria rio-grandense.

Embora muitas fábricas européias trabalhem certamente, em muito maior escala, creio, entretanto, dever chamar a atenção para a produção da fábrica alemã de Pelotas.

Ela produziu, no ano: 30.000 caixas de 48 libras de sabão, 12.000 caixas de 26 libras de velas, além de 2.500 arrobas de gordura líquida ou oleo animal de cascos e unhas e 2.000 arrobas de cola.

As caixas e recipientes para a embalagem dos produtos são feitos no proprio local. Este negócio por si pede uma secção especial, um negócio especial, que devia exigír tôda a atenção de um gerente. De fato, uma parte da instalação é uma completa fábrica de caixas.

$\mathbb{E}$ em todos êsses muitos esforços materiais, em parte puramente materiais, o nosso amigo, no seu estabelecimento isolado e bastante afastado da humanidade mais fiaca, soube formar a civilização e a condura do europeu educado que êle trouxe consigo da pátria circunstancia pela qual tho dedico a minha particular estima.

Para de algum modo ter uma vista de tốca a região e da cidado de Pelotas, situada na planície, fiz uma excursão a uma colina próyima.

Entre os rios Piratin e Camaquã - não confund̛llos com os ris do mesmo nome na parte ocidental da província, que desembocam no Uruguai - se estende mas ou menos paralelamente a lagoa, a umas dez léguas de Peloras, uma cordilipeira, a Serra dos Tapes, cujos contrafortes se aproximam até a duas léguas da referida cidade e ali formam uma pequena cadeia de elevações que, pela sua graciosa aparência, é chamada Nionte Bonito. 
O caminho para lá não é pròpriamente bonito. Abre-se uma planície bastante êrma; aliás se vêem muitas plantações e sítios de boa aparência, mas o conjunto é pobre. Notam-se até araucárias isoladas; grandes massas de cactos e mimosas e muitos gravatás concorrem para dar a completa expressão de inospitalidade. Em muitos lugares o solo parece pedregoso e nele só medra erva curta. Todavia, apesar do solo e do fim de outono, floresciam abundantemente em tôda parte as inevitáveis oxalis. Em algumas depressões encontrei formas de plantas perfeitamente semelhantes às nossas sagitárias nórdicas, mas sem flores, de modo que não pude identificá-las.

Aqui devo recordar também uma espécie de galha ou excrescência, que frequientemente encontrei neste lado de Pelotas. Pela picada e os ovos de um icneumonídeo ou antes de um cinipídio, forma-se, nos ramos de um arbusto, uma excrescência esférica de natureza sólida, lenhosa, a qual, por causa de sua forma perfeitamente regular e sua grande abundância naquele arbusto, poderia ser considerado como um fruto dêle. $O$ povo grealmente chama o arbusto de galha. Durante o seu desenvolvimento se desenha muito regularmente, ao lado dessa excrescência, um pequeno círculo, que cada vez se torna mais distinto, e forma um opérculo, que cai exatamente no tempo em que o insecto sai do ovo. No buraco redondo, como se fôra feito cuidadosamente com uma faca, encontra-se ainda, freqüentemente, a pele da larva do insecto que voou.

$E^{\prime}$ ' digno de nota que essas esferas não sejam formadas nem pela entrecasca, nem pela casca, mas pelo lenho do arbusto. Assim, cortando-se uma esfera desenvolvida, porém ainda não aberta, chega-se, através de casca, dá entrecasca e do lenho, a uma cavidade perfeitamente esférica, na qual se encontram garalmente duas a trếs larvas do insecto. Em sua morada vegetal, o insecto nada faz, absolutamente, para abrir o opérculo, pois a deiscência dêste coincide com a eclosão daquêle. Encontrei esferas em que o opérculo já estava quase solko; cortando-as encontrei o insecto também quase a ponto. Essa coincidência entre a desscência do opérculo e a madureza do pequeno animal é muito singular.

O moní Bonito, a quem dêle se aproxima, não parece merecer o nome de monte. Em sua encosta inferior desce um pequeno bosque onde se encontra algum granito decomposto, densamente coberto de líquens, cheios de cactos redondos em suas fendas. No alto do monte; ao contrário, ostentam-se seis a oito figueiras bravas, que esten¿em as suas copas magníficas em tôdas as direçōes. A copa de uma dessas árvores tinha 64 pés de diâmetro; até a 4 pés acima da terra pondem os'seus extensos ramos. O tronco curto parece com várias rafzes enrodithadas acima da terra, que abraçam e prendem entre si uma grande pedra. A árvore $\Theta$ a pedra recordam uma metamorfose de Ovídio. Uma Oréada de endurecido coração lutando entre os ardentes braços de um sátiro, invocou Diana e a cólera da deusa 
transformou o escândalo em pedra e árvore: tudo isso no monte Bonito, a duas milhas de Pelotas, a degoladora de bois.

Magnificas árvores, essas figueiras bravas! Um tronco geralmente curto, irregular, suporta uma densa copa, às vêzes redonda, mas goralmente chata e exrensa, cujas fôlhas grandes e abundantes não dessemelham das fôlhas das murtas. Há em seus ramos uma quantidade extraordinária de frutos sésseis, cujas sementes periféricas as caracterizam como legítimas figueiras, por mais diferentes que parecam com os frutos e as árvores da figueira nobre. Sóbre colinas, ao lado de remotas estâncias, em tranquilos riachos dão a impressão de solitude e abandono. Assim também as árvores no monte Bonito! Embora ali haja, ao lado das figueiras, uma casinha com algumas palmeiras, não deixa de ser evidente a expressão de êrmo. Sôbre a planície espraiam-se os olhos até à distante Pelotas! No horizonte estende-se a lagoa dos Patos e aparece o longíquo oceano. Ao longe brilham as massas brancas amareladas da areia gorda; julga-se avistar à margem do oceano ou o princípio de um Saara.

Por outro lado, para o interior, embora à primeira vista não se reconheça muito cultura, a paisagem é mais fresca. As longas cadeias da serra dos Tapes entrecortam-se; as matas e desfiladeiros formam uma variedade unialade, da qual, como sinal de uma civilização incipiente, sobe, en muitos pontos, significativas colunas de fumaça.

Regressando do monte Ronito para Pelotas, encontramos entre os seus 7.000 habitantes - a cidade parece ter sido traçada para 20 a 30 mil moradores - alguns alemāes, que parecem viver em boas condições e gozar de geral estima. Um velho senhor de Freitas é natural de Hesse e em agradecimento de ter êle dirigido os seus negócios na província, honkada e laboriosamente por tiinta e quatro anos, the trocaram o nome de Freitag pelo nome mais corrente de Freitas, com o predicado de nobreza; o honrado alemäo recebeu-me muito amàvelmente. Em casa do senhor Bärtegen, de EIsfleth, cônsul do gräo-ducado de Olderburgo em Pelotas - tão profuncamente ja penetran no Brasil as relaçôes políticas alemães - passei horas agraćáveis e gozei boa música de piano tocada pela sua amável e modesta espôsa, que recebeu educação completa e é îmãa da jovem senhora de São Gabriel, a espôsa do advogado francês dali.

De rnuito bom grado relembro êsses fatos talvez insignificantes em que aparecem o caráter, a civilidade e a educação de elementos europeus em lugares bastante remotos. Quem, como europeu, percorre regiōes longíquas, onde as relações sociais ainda estão confusas, sentirá como eu, que nunca fiquei indiferente em tais momentos e ante tais monumentis. 